\title{
\begin{tabular}{l|l} 
Mitraries & DSpace@MIT
\end{tabular}
}

\author{
MIT Open Access Articles
}

\section{Determining the Origins of Advective Heat Transport Convergence Variability in the North Atlantic}

The MIT Faculty has made this article openly available. Please share how this access benefits you. Your story matters.

Citation: Buckley, Martha W., Rui M. Ponte, Gael Forget, and Patrick Heimbach. “Determining the Origins of Advective Heat Transport Convergence Variability in the North Atlantic." J. Climate 28, no. 10 (May 2015): 3943-3956. (C) 2015 American Meteorological Society

As Published: http://dx.doi.org/10.1175/jcli-d-14-00579.1

Publisher: American Meteorological Society

Persistent URL: http://hdl.handle.net/1721.1/100468

Version: Final published version: final published article, as it appeared in a journal, conference proceedings, or other formally published context

Terms of Use: Article is made available in accordance with the publisher's policy and may be subject to US copyright law. Please refer to the publisher's site for terms of use. 


\title{
Determining the Origins of Advective Heat Transport Convergence Variability in the North Atlantic
}

\author{
Martha W. BuckleY* AND Rui M. Ponte \\ Atmospheric and Environmental Research, Lexington, Massachusetts \\ GAËL FORGET AND PATRICK HEIMBACH ${ }^{+}$ \\ Department of Earth, Atmospheric, and Planetary Science, Massachusetts Institute of Technology, Cambridge, Massachusetts
}

(Manuscript received 23 June 2014, in final form 30 January 2015)

\begin{abstract}
A recent state estimate covering the period 1992-2010 from the Estimating the Circulation and Climate of the Ocean (ECCO) project is utilized to quantify the roles of air-sea heat fluxes and advective heat transport convergences in setting upper-ocean heat content anomalies $H$ in the North Atlantic Ocean on monthly to interannual time scales. Anomalies in (linear) advective heat transport convergences, as well as Ekman and geostrophic contributions, are decomposed into parts that are due to velocity variability, temperature variability, and their covariability. Ekman convergences are generally dominated by variability in Ekman mass transports, which reflect the instantaneous response to local wind forcing, except in the tropics, where variability in the temperature field plays a significant role. In contrast, both budget analyses and simple dynamical arguments demonstrate that geostrophic heat transport convergences that are due to temperature and velocity variability are anticorrelated, and thus their separate treatment is not insightful. In the interior of the subtropical gyre, the sum of air-sea heat fluxes and Ekman heat transport convergences is a reasonable measure of local atmospheric forcing, and such forcing explains the majority of $H$ variability on all time scales resolved by ECCO. In contrast, in the Gulf Stream region and subpolar gyre, ocean dynamics are found to be important in setting $H$ on interannual time scales. Air-sea heat fluxes damp anomalies created by the ocean and thus are not set by local atmospheric variability.
\end{abstract}

\section{Introduction}

The goal of this paper is to address the role of local atmospheric forcing and ocean dynamics in setting intraannual to interannual variability of upper-ocean heat content (UOHC) in the North Atlantic Ocean. Specifically, we investigate the origin of advective heat transport convergences and estimate the portion of these convergences that reflect local atmospheric forcing (Ekman

\footnotetext{
* Current affiliation: Department of Atmospheric, Oceanic and Earth Sciences, George Mason University, Fairfax, Virginia.

${ }^{+}$Additional affiliation: Institute for Computational Engineering and Sciences, and Jackson School of Geosciences, The University of Texas at Austin, Austin, Texas.

Corresponding author address: Martha W. Buckley, Dept. of Atmospheric, Oceanic and Earth Sciences, George Mason University, 284 Research Hall Mail Stop 2B3, 4400 University Drive, Fairfax, VA 22030.

E-mail: marthabuckley@gmail.com
}

transports) versus active (geostrophic) ocean dynamics. To the extent that ocean dynamics contribute significantly to this convergence, the ocean may have a sizable impact on atmospheric climate variability.

Our work closely follows Buckley et al. (2014, henceforth referred to as BPFH), who utilize an ocean state estimate produced by the Estimating the Circulation and Climate of the Ocean (ECCO) project to quantify the upper-ocean heat budget in the North Atlantic. BPFH introduce three novel techniques for understanding UOHC variability: 1) the heat budget is integrated over the maximum climatological mixed layer depth, yielding budgets that are relevant for explaining sea surface temperature (SST) while avoiding strong contributions from vertical diffusion and mixed layer entrainment, 2) advective convergences are separated into Ekman and geostrophic parts in an attempt to better distinguish between local forcing and contributions from ocean dynamics, and 3) air-sea heat fluxes and Ekman advection are combined into one "local forcing" term.

Here we extend the work of BPFH by further decomposing advective heat transport convergences, as 
well as Ekman and geostrophic convergences, into parts that are due to velocity variability, temperature variability, and their covariability (section 3 ). This decomposition is motivated by numerous studies that separate meridional ocean heat transports (OHT) in the same manner. Such studies generally find that anomalies in meridional OHT and its convergences are dominated by variability in the velocity field in the tropics and subtropics (Jayne and Marotzke 2001; Johns et al. 2011) while temperature variability and covariability between temperature and velocity play a nonnegligible role at high latitudes (Dong and Sutton 2002; Piecuch and Ponte 2012). Here, rather than focusing on meridional OHT and its convergences in latitude bands, we focus on spatial maps of advective heat transport convergences, as in Doney et al. (2007). This approach may be better suited for understanding UOHC anomalies in the North Atlantic because the dominant modes of UOHC variability do not follow latitude bands (e.g., the tripole SST anomalies that are due to the North Atlantic Oscillation; see Cayan 1992a,b). As an extension to the results presented in Doney et al. (2007), we also decompose the Ekman and geostrophic heat transport convergences into portions that are due to variability in the velocity field, temperature field, and their covariability (see section 3 ).

In section 4, we estimate the role of local atmospheric forcing in setting UOHC anomalies. We assess the "null hypothesis" that UOHC anomalies are due to local air-sea heat fluxes and Ekman heat transport convergences resulting from Ekman mass transport variability. In section 5, the North Atlantic is divided into several dynamically distinct regions, and the important terms in the $\mathrm{UOHC}$ budget in each of these regions are examined. The ability of local atmospheric forcing to explain the observed UOHC variability is assessed as a function of region and time scale. The main conclusions of our work are discussed in section 6 .

\section{Review of ECCO estimate and budget techniques}

Our study makes use of a new state estimate produced by the ECCO-Production project (henceforth ECCO v4) described by Wunsch and Heimbach (2013), Forget et al. (2015, manuscript submitted to Geosci. Model Dev.), Speer and Forget (2013), Forget and Ponte (2015, manuscript submitted to Prog. Oceanogr.), and BPFH. For consistency with $\mathrm{BPFH}$, the present analysis is based on a preliminary ECCO v4 solution (revision 3, iteration 3), which covers the period of 1992-2010. Our choice is motivated by two important features of ECCO estimates: 1) as compared with free-running coupled or ocean-only general circulation models, ECCO estimates are consistent (within derived uncertainty estimates) with most existing ocean observations and 2) in contrast to reanalysis products based upon sequential methods, adjoint-based ECCO estimates are free of artificial internal heat and freshwater sources/sinks and fulfill known conservation laws exactly (Wunsch and Heimbach 2013). This property enables consistent term-by-term diagnostics of the heat equation.

As in BPFH, we define UOHC as the integral of the heat contained in the layer between the surface $\eta$ and the maximum climatological mixed layer depth $D$ :

$$
H \equiv \rho_{o} C_{p} \int_{-D}^{\eta} \theta d z
$$

where $\theta$ is temperature, $\rho_{o}$ is the mean density, and $C_{p}$ is the heat capacity. It is useful to recall the following results from the budget analyses presented in BPFH [see their Eq. (2) for the conservation equation for $H]$ :

1) While air-sea heat fluxes $Q_{\text {net }}$ (Fig. 1a) are the dominant term in setting the tendency of $H\left(H_{t}\right)$ over the basin interiors, advective heat transport convergences $C_{\text {adv }}$ play a significant role in creating variance of $H_{t}$ in regions of strong currents/fronts.

2) Outside shallow boundary regions and the Mann eddy region (centered at $42^{\circ} \mathrm{N}, 44^{\circ} \mathrm{W}$ ), $C_{\text {adv }}$ is well approximated by the linear advective convergence,

$$
C_{\text {lin }}(\mathbf{u}, \theta)=-\rho_{o} C_{p} \int_{-D}^{\eta} \nabla \cdot(\mathbf{u} \theta) d z,
$$

where $\theta$ and $\mathbf{u}$ are monthly means ${ }^{1}$ of the temperature field and the explicit three-dimensional velocity field, respectively.

3) In most regions, $C_{\text {lin }}$ (Fig. 1b) can be decomposed into Ekman $\left(C_{\mathrm{ek}}\right)$ and geostrophic $\left(C_{g}\right)$ parts, as shown in Fig. 1e. Both $C_{\mathrm{ek}}$ (Fig. 1c) and $C_{g}$ (Fig. 1d) are largest along the Gulf Stream path and in boundary regions, but $C_{\mathrm{ek}}$ is also significant in gyre interiors. The terms $C_{\mathrm{ek}}$ and $C_{g}$ include both horizontal and vertical convergences. Vertical velocities $w_{\mathrm{ek}}$ and $w_{g}$ are calculated from Ekman $\left(\mathbf{u}_{\mathrm{ek}}\right)$ and geostrophic $\left(\mathbf{u}_{g}\right)$ horizontal velocities, respectively, using the continuity equation [see Eqs. (6)-(8) in BPFH].

In this paper we focus on regions where 1) diffusion and eddy-driven (bolus) transports can be neglected in the heat budget and 2) $C_{\mathrm{lin}} \approx C_{\mathrm{ek}}+C_{g}$. In these regions, which include much of the North Atlantic basin outside of shallow boundary regions and the Mann eddy region, the fraction of the variance $^{2}$ of $H_{t}$ explained by $C_{\mathrm{ek}}+C_{g}+Q_{\mathrm{net}} \approx 1$ (Fig. 1f).

\footnotetext{
${ }^{1}$ In contrast to BPFH, we drop overbars for denoting monthly mean values.

${ }^{2}$ The fraction of the variance $\sigma^{2}$ of a quantity $X$ explained by an estimate $Y$ is given by $f=1-\left[\sigma_{(X-Y)}^{2} / \sigma_{X}^{2}\right]$, where $\sigma_{X}^{2}$ is the variance of $X$ and $\sigma_{(X-Y)}^{2}$ is the variance of $X-Y$.
} 

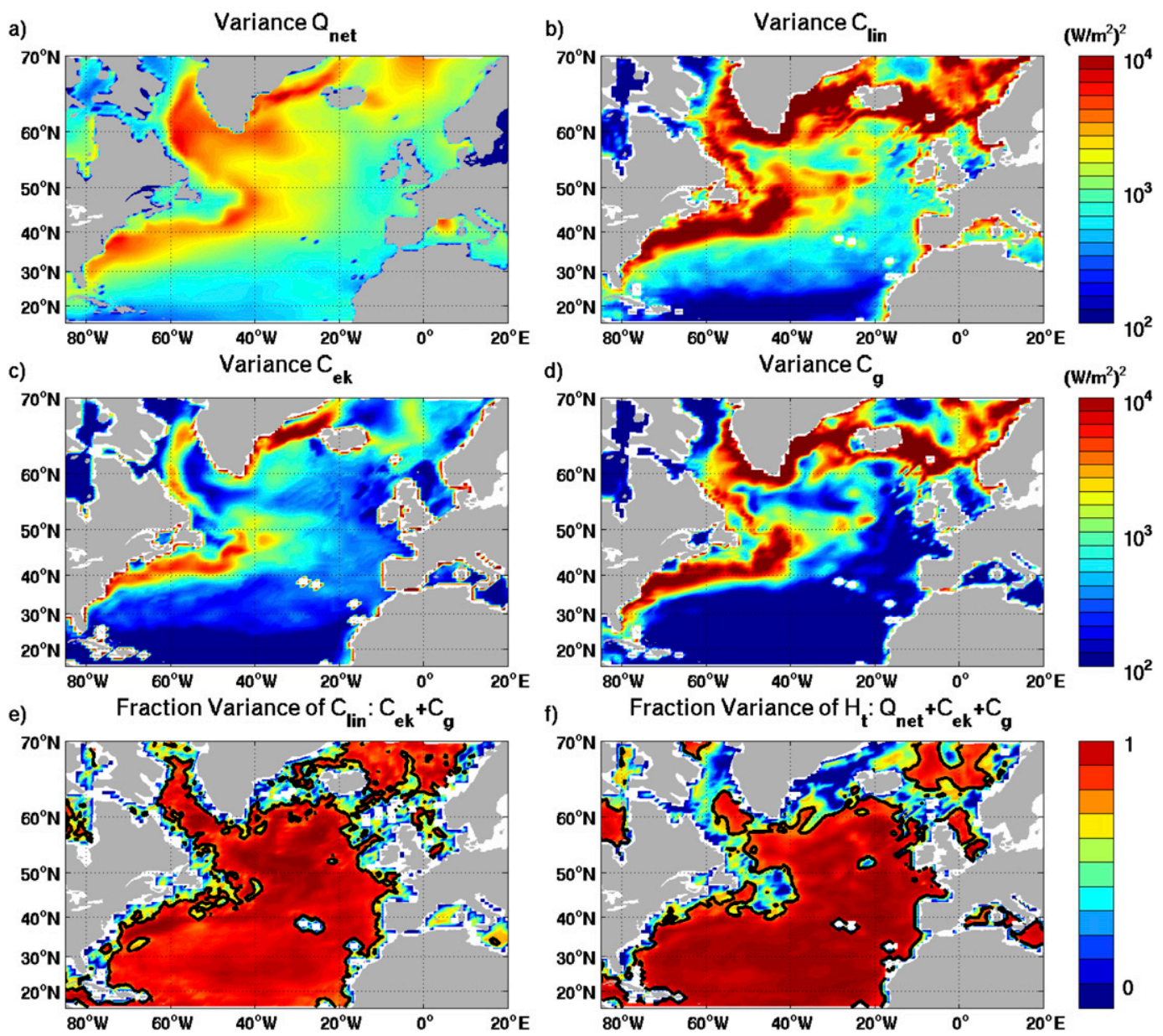

FIG. 1. Variance of monthly anomalies of (a) $Q_{\text {net }}$, (b) $C_{\text {lin }}$, (c) $C_{\mathrm{ek}}$, and (d) $C_{g}$. Note the logarithmic color scale. Also shown are maps of the fraction of the variance of (e) $C_{\mathrm{lin}}$ explained by $C_{\mathrm{ek}}+C_{g}$ and (f) $H_{t}$ explained by $C_{\mathrm{ek}}+$ $C_{g}+Q_{\text {net }}$. Black contours are at levels of 0.7.

Before proceeding, it is important to recall that, through the optimization process, atmospheric forcings, initial conditions, and model parameters (e.g., interior mixing coefficients) are adjusted (within error bars) to make the ECCO estimates consistent with ocean observations (also within error bars). The firstguess atmospheric forcing is given by the atmospheric state (surface air temperature, specific humidity, precipitation, and downwelling radiation) and wind stress vector fields from the European Centre for MediumRange Weather Forecasts interim reanalysis (ERAInterim). Momentum forcing is directly applied as wind stress, and wind stress is adjusted by the optimization. Bulk formulas are used to compute the upward mass and buoyancy fluxes from ocean temperature, atmospheric temperature, humidity, downward radiation, and wind speed. All atmospheric variables input into the bulk formulas are adjusted, with the exception of wind speed.
Here we address the impact of optimization on the heat budget. Our goals are to determine 1) how variances of changes in the heat budget resulting from optimization compare with the variances of the terms in the heat budget and 2) what portion of changes resulting from optimization are attributable to adjustments to atmospheric forcing (e.g., wind stress and air-sea heat fluxes). To this end, we quantify the changes in $C_{\mathrm{ek}}$ and $Q_{\text {net }}$ resulting from optimization. We define $\Delta Q_{\text {net }}=Q_{\text {net }}-Q_{\text {net }}^{\text {no }}$ and $\Delta C_{\text {ek }}=C_{\text {ek }}-C_{\mathrm{ek}}^{\mathrm{no}}$, where the superscript "no" indicates quantities from the nonoptimized solution. The term $\Delta Q_{\text {net }}$ includes changes in air-sea heat fluxes resulting from adjustments to inputs into the bulk formula (atmospheric temperature, humidity, and downward radiation), as well as changes in the ocean temperature field that are due to optimization. The term $\Delta C_{\mathrm{ek}}$ includes changes that are due to Ekman mass transports (due to adjustments of the wind stress field), as well as changes in 
a)

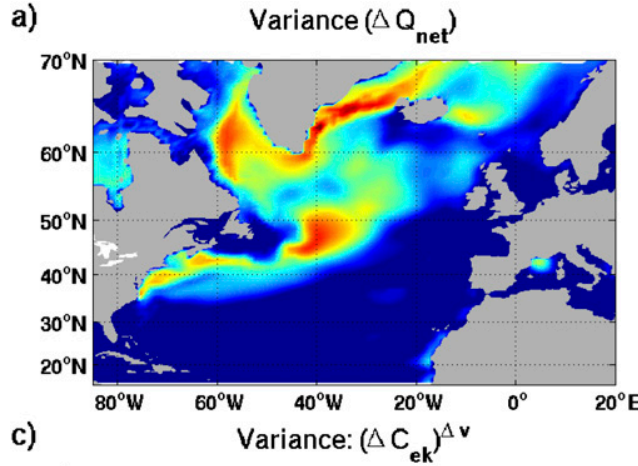

c)

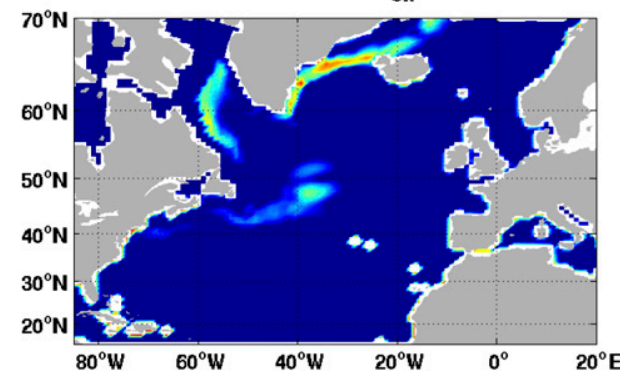

b)

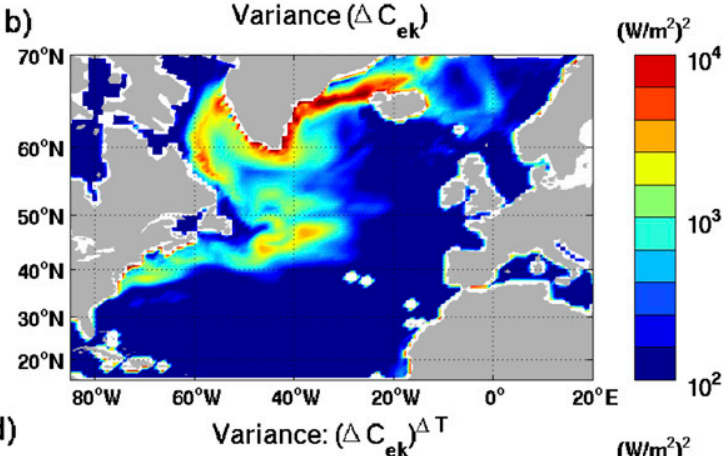

d)

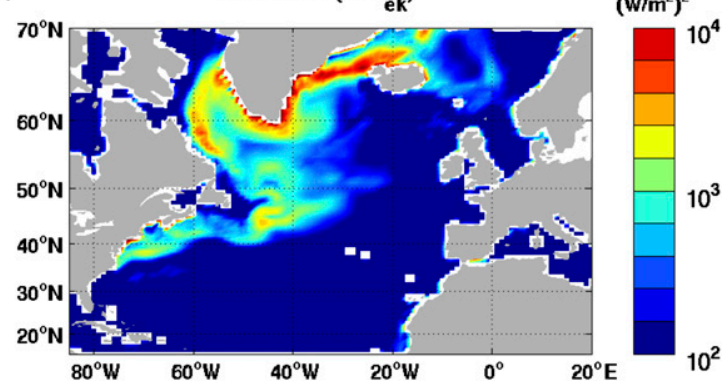

FIG. 2. Impact of the optimizations procedure on $Q_{\text {net }}$ and $C_{\text {ek }}$ : variances of monthly anomalies of (a) $\Delta Q_{\text {net }}$, (b) $\Delta C_{\mathrm{ek}}$, (c) $\left(\Delta C_{\mathrm{ek}}\right)^{\Delta v}$, and (d) $\left(\Delta C_{\mathrm{ek}}\right)^{\Delta T}$. These should be compared with the variances of monthly anomalies of $Q_{\text {net }}$ and $C_{\text {ek }}$ shown in Figs. 1a and 1c.

the ocean temperature field resulting from optimization. We separate $\Delta C_{\mathrm{ek}}$ into components:

$$
\begin{aligned}
\Delta C_{\mathrm{ek}}= & \underbrace{C_{\mathrm{ek}}\left(\Delta \mathbf{u}_{\mathrm{ek}}, \Delta w_{\mathrm{ek}}, \theta^{\mathrm{no}}\right)}_{\left(\Delta C_{\mathrm{ek}}\right)^{\Delta v}}+\underbrace{C_{\mathrm{ek}}\left(\mathbf{u}_{\mathrm{ek}}^{\mathrm{no}}, w_{\mathrm{ek}}^{\mathrm{no}}, \Delta \theta\right)}_{\left(\Delta C_{\mathrm{ek}}\right)^{\Delta T}} \\
& +\underbrace{C_{\mathrm{ek}}\left(\Delta \mathbf{u}_{\mathrm{ek}}, \Delta w_{\mathrm{ek}}, \Delta \theta\right)}_{\left(\Delta C_{\mathrm{ek}}\right)^{\Delta \Delta \Delta T}},
\end{aligned}
$$

where $\Delta \mathbf{u}_{\mathrm{ek}}=\mathbf{u}_{\mathrm{ek}}-\mathbf{u}_{\mathrm{ek}}^{\mathrm{no}}, \Delta w_{\mathrm{ek}}=w_{\mathrm{ek}}-w_{\mathrm{ek}}^{\mathrm{no}}$, and $\Delta \theta=$ $\theta-\theta^{\text {no }}$. The term $\left(\Delta C_{\mathrm{ek}}\right)^{\Delta v}$ involves only changes in Ekman mass transports resulting from adjustments to wind stress; changes in the ocean temperature field that play a role in the latter two terms are not directly attributable to changes in atmospheric forcing. Variances of monthly anomalies (seasonal cycle removed) of $\Delta Q_{\text {net }}$ and $\Delta C_{\text {ek }}$ are substantial in the Gulf Stream region, the Mann eddy region, and the western subpolar gyre (cf. variances of $\Delta Q_{\text {net }}$ and $\Delta C_{\mathrm{ek}}$ in Figs. 2a,b with variances of $Q_{\text {net }}$ and $C_{\mathrm{ek}}$ in Figs. 1a,c). The terms $\left(\Delta C_{\mathrm{ek}}\right)^{\Delta v}$ (Fig. 2c) and $\left(\Delta C_{\mathrm{ek}}\right)^{\Delta v \Delta T}$ (not shown) are much smaller than $\left(\Delta C_{\mathrm{ek}}\right)^{\Delta T}$ (Fig. 2d). Therefore, direct changes in the wind stress resulting from the optimization procedure play a second-order role in variability of $C_{\mathrm{ek}}$. The larger adjustments in $Q_{\text {net }}$ in comparison with $C_{\mathrm{ek}}^{\Delta v}$ are in accord with the expectation that quantities determining air-sea fluxes (including variable ocean temperatures) are more uncertain than wind stress and associated Ekman mass transports. In summary, optimization quantitatively impacts the $H$ budget in some ocean regions, including the Gulf Stream region, the Mann eddy region, and the western subpolar gyre. These quantitative changes are the result of adjustments to initial conditions, inputs into the bulk formulas, and model parameters. Direct changes in wind stress fields that are due to optimization and their impact on Ekman transports play a negligible role.

\section{Roles of temperature and velocity variability}

Following Doney et al. (2007), we decompose $C_{\text {lin }}$ into convergences due to variability in velocity, temperature, and their covariability:

$$
C_{\operatorname{lin}}=C_{\operatorname{lin}}(\overline{\mathbf{u}}, \bar{\theta})+\underbrace{C_{\operatorname{lin}}\left(\mathbf{u}^{\prime}, \bar{\theta}\right)}_{C_{\operatorname{lin}}^{v}}+\underbrace{C_{\operatorname{lin}}\left(\overline{\mathbf{u}}, \theta^{\prime}\right)}_{C_{\operatorname{lin}}^{T}}+\underbrace{C_{\operatorname{lin}}\left(\mathbf{u}^{\prime}, \theta^{\prime}\right)}_{C_{\operatorname{lin}}^{V T}} .
$$

Here overbars denote means over the 19-yr ECCO estimate and primes denote deviations from these means. Figures $3 \mathrm{a}-\mathrm{c}$ show variances $\sigma^{2}$ of monthly anomalies (seasonal cycle removed by subtracting the mean monthly climatology) of $C_{\operatorname{lin}}^{v}, C_{\operatorname{lin}}^{T}$, and $C_{\operatorname{lin}}^{v T}$ normalized by the variance of $C_{\operatorname{lin}}$ (shown in Fig. 1b). The term $C_{\operatorname{lin}}^{v}$ is the dominant term over most of the interior of the subtropical gyre and the southeastern portion of the subpolar gyre 

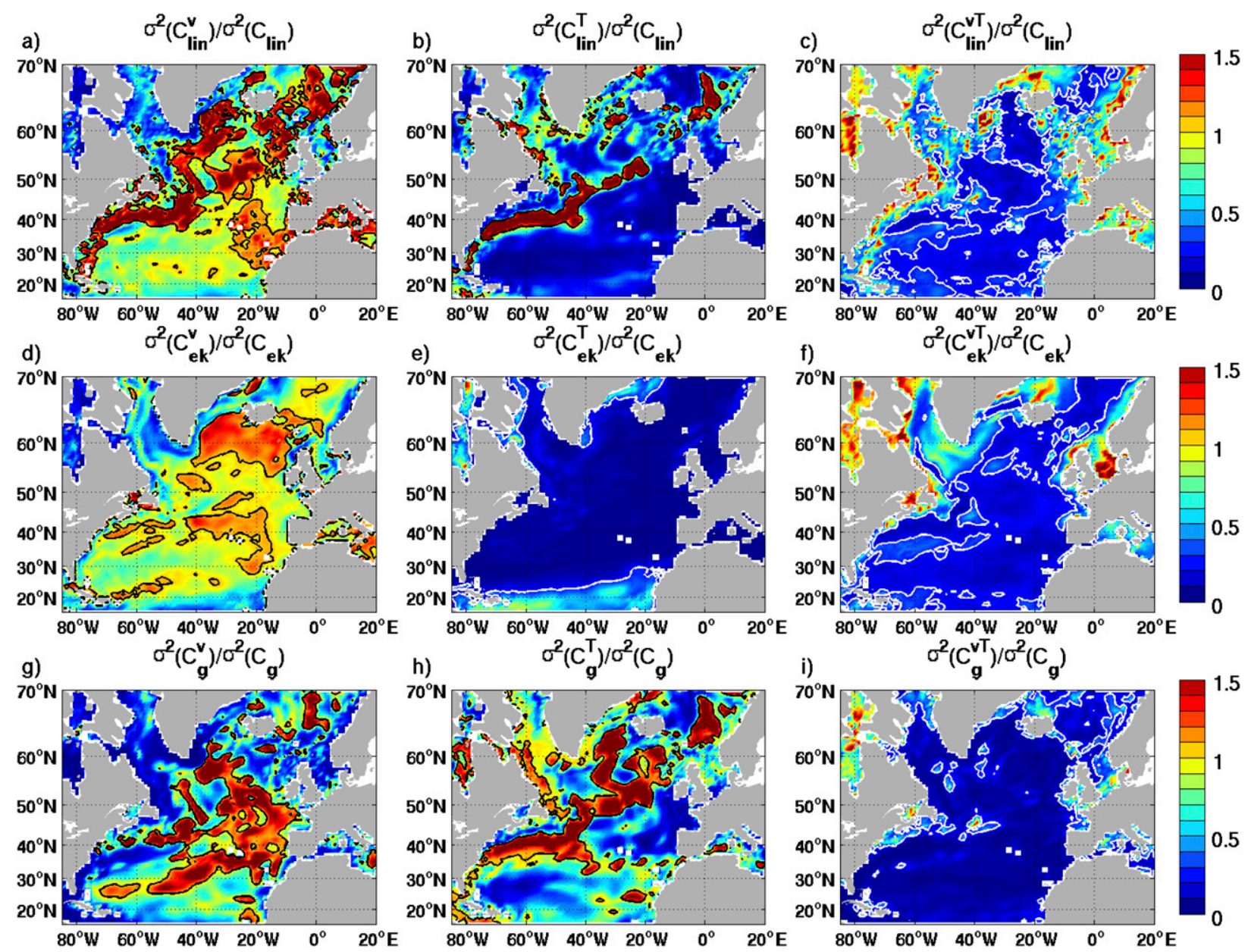

FIG. 3. Maps of ratios of variances $\sigma^{2}$ that show the portion of the variability of $C_{\text {lin }}, C_{\text {ek }}$, and $C_{g}$ (Figs. $1 \mathrm{~b}$-d) that is due to variability in the temperature field, velocity field, and their covariability: (a) $\sigma^{2}\left(C_{\operatorname{lin}}^{v}\right) / \sigma^{2}\left(C_{\operatorname{lin}}\right),(\mathrm{b}) \sigma^{2}\left(C_{\operatorname{lin}}^{T}\right) / \sigma^{2}\left(C_{\operatorname{lin}}\right),(\mathrm{c}) \sigma^{2}\left(C_{\operatorname{lin}}^{v T}\right) / \sigma^{2}\left(C_{\text {lin }}\right),(\mathrm{d}) \sigma^{2}\left(C_{\mathrm{ek}}^{v}\right) /$ $\sigma^{2}\left(C_{\mathrm{ek}}\right),(\mathrm{e}) \sigma^{2}\left(C_{\mathrm{ek}}^{T}\right) / \sigma^{2}\left(C_{\mathrm{ek}}\right)$, (f) $\sigma^{2}\left(C_{\mathrm{ek}}^{v T}\right) / \sigma^{2}\left(C_{\mathrm{ek}}\right),(\mathrm{g}) \sigma^{2}\left(C_{g}^{v}\right) / \sigma^{2}\left(C_{g}\right)$, (h) $\sigma^{2}\left(C_{g}^{T}\right) / \sigma^{2}\left(C_{g}\right)$, and (i) $\sigma^{2}\left(C_{g}^{v T}\right) / \sigma^{2}\left(C_{g}\right)$. White contours in (c),(e),(f), and (i) are at a level of 0.2, and black contours in (a),(b),(d),(g), and (h) are at a level of 1.

(see Fig. 4a). Over the Gulf Stream path and portions of the subpolar gyre, both $C_{\text {lin }}^{v}$ and $C_{\text {lin }}^{T}$ contribute to $C_{\text {lin }}$ (Fig. 4b). Ratios $\sigma^{2}\left(C_{\text {lin }}^{v}\right) / \sigma^{2}\left(C_{\text {lin }}\right)$ and $\sigma^{2}\left(C_{\text {lin }}^{T}\right) / \sigma^{2}\left(C_{\text {lin }}\right)$ are greater than 1 (Figs. 3a,b), suggesting that these terms are anticorrelated (Fig. 4c). The importance of both temperature and velocity variability in setting advective convergences in regions of currents/fronts, as well as the anticorrelation between these terms, was previously noted by Dong and Sutton (2002) and Doney et al. (2007). The term $C_{\text {lin }}^{v T}$ only plays a role in setting $C_{\text {lin }}$ in shallow boundary regions (Figs. $3 \mathrm{c}$ and $4 \mathrm{~b}$ ), and in these regions $C_{\text {lin }}^{v T}$ and $C_{\text {lin }}^{v}$ are anticorrelated (Fig. 4d).

To better understand the reason for the relative contributions of $C_{\text {lin }}^{v}$ and $C_{\text {lin }}^{T}$ to $C_{\text {lin }}$, as well as their anticorrelation, we separate $C_{\mathrm{ek}}$ and $C_{g}$ (whose sum well reproduces $C_{\text {lin }}$ in most regions) into convergences that are due to temperature variability, velocity variability, and their covariability:

$$
\begin{gathered}
C_{\mathrm{ek}}\left(\mathbf{u}_{\mathrm{ek}}, w_{\mathrm{ek}}, \theta\right)=C_{\mathrm{ek}}\left(\overline{\mathbf{u}}_{\mathrm{ek}}, \bar{w}_{\mathrm{ek}}, \bar{\theta}\right)+\underbrace{C_{\mathrm{ek}}\left(\mathbf{u}_{\mathrm{ek}}^{\prime}, w_{\mathrm{ek}}^{\prime}, \bar{\theta}\right)}_{C_{\mathrm{ek}}^{v}}+\underbrace{C_{\mathrm{ek}}\left(\overline{\mathbf{u}}_{\mathrm{ek}}, \bar{w}_{\mathrm{ek}}, \theta^{\prime}\right)}_{C_{\mathrm{ek}}^{T}}+\underbrace{C_{\mathrm{ek}}\left(\mathbf{u}_{\mathrm{ek}}^{\prime}, w_{\mathrm{ek}}^{\prime}, \theta^{\prime}\right)}_{C_{\mathrm{ek}}^{v T}} \\
C_{g}\left(\mathbf{u}_{g}, w_{g}, \theta\right)=C_{g}\left(\overline{\mathbf{u}}_{g}, \bar{w}_{g}, \bar{\theta}\right)+v \underbrace{C_{g}\left(\mathbf{u}_{g}^{\prime}, w_{g}^{\prime}, \bar{\theta}\right)}_{C_{g}^{v}}+\underbrace{C_{g}\left(\overline{\mathbf{u}}_{g}, \bar{w}_{g}, \theta^{\prime}\right)}_{C_{g}^{T}}+\underbrace{C_{g}\left(\mathbf{u}_{g}^{\prime}, w_{g}^{\prime}, \theta^{\prime}\right)}_{C_{g}^{v T}} .
\end{gathered}
$$


a)

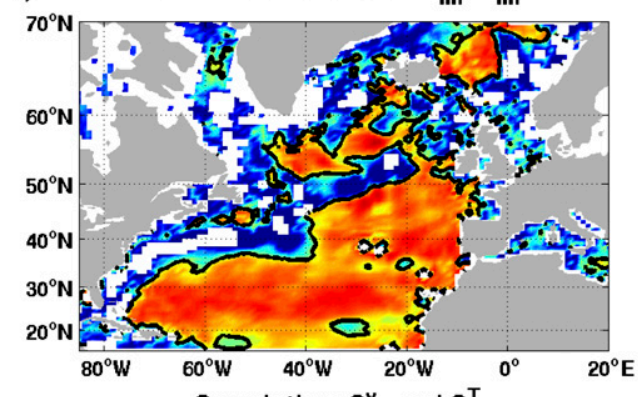

c)

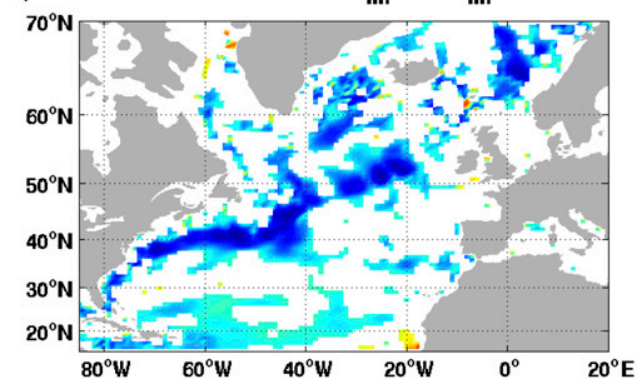

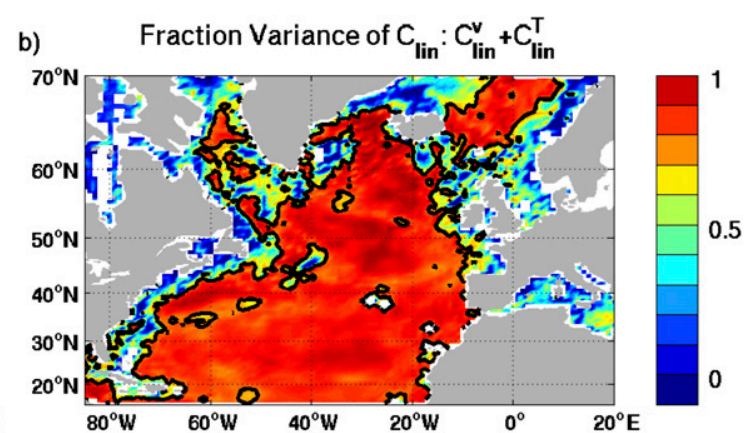

d)

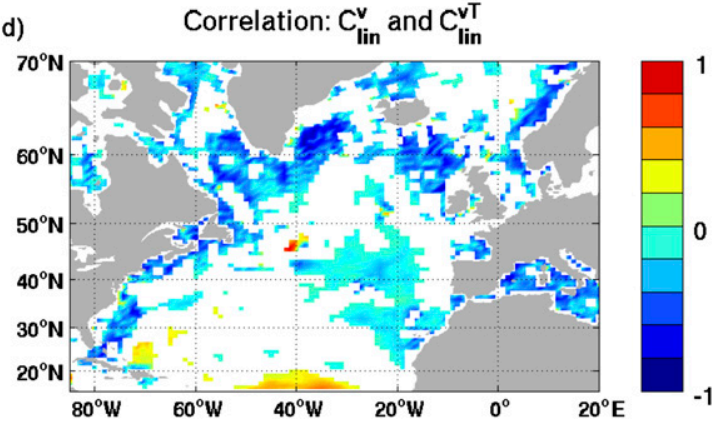

FIG. 4. Maps showing the fraction of the variance of $C_{\text {lin }}$ explained by (a) $C_{\operatorname{lin}}^{v}$ and (b) $C_{\text {lin }}^{v}+C_{\text {lin }}^{T}$. Black contours are at levels of 0.5 in (a) and 0.7 in (b). Also shown are correlations (at each spatial location) between (c) $C_{\text {lin }}^{v}$ and $C_{\text {lin }}^{T}$ and (d) $C_{\operatorname{lin}}^{v}$ and $C_{\text {lin }}^{v T}$. Only correlations that are significant at the $95 \%$ confidence level are plotted.

In most regions the variance of monthly anomalies of $C_{\mathrm{ek}}$ is dominated by $C_{\mathrm{ek}}^{v}$ (Figs. $3 \mathrm{~d}$ and 5a), which confirms the hypothesis of BPFH that $C_{\mathrm{ek}}$ is indeed primarily driven by local wind variability rather than changes in the temperature field. However, $C_{\mathrm{ek}}^{T}$ plays a significant role in the tropics (Fig. 3e), in accord with the results of Foltz and McPhaden (2006). The term $C_{\mathrm{ek}}^{v T}$ makes contributions in the Labrador Sea and Nordic seas, shallow
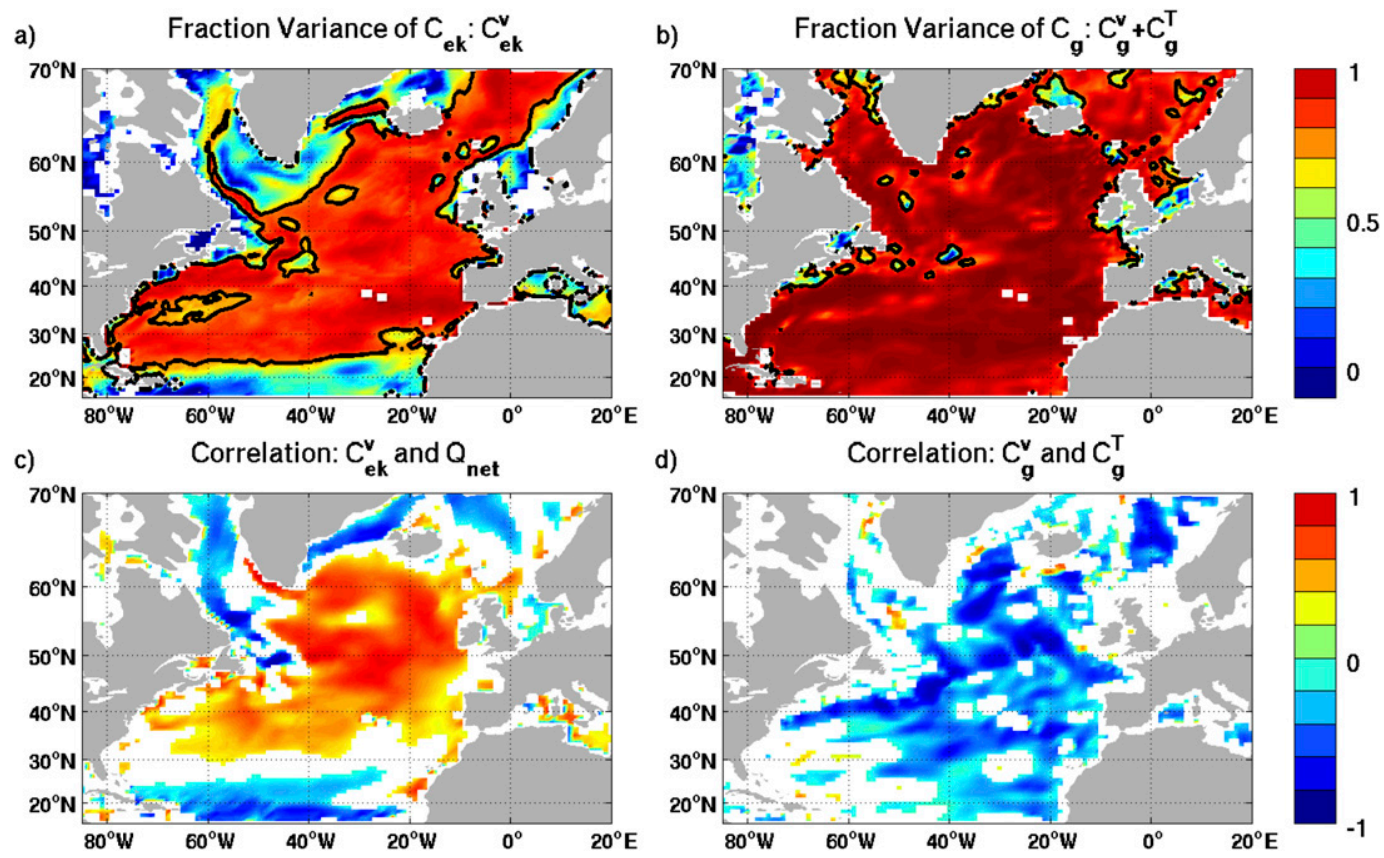

FIG. 5. Maps showing the fraction of the variance of (a) $C_{\mathrm{ek}}$ explained by $C_{\mathrm{ek}}^{v}$ and (b) $C_{g}$ explained by $C_{g}^{v}+C_{g}^{T}$. Black contours are at levels of 0.7. Also shown are correlations (at each spatial location) between (c) $C_{\mathrm{ek}}^{v}$ and $Q_{\mathrm{net}}$ and (d) $C_{g}^{v}$ and $C_{g}^{T}$. Only correlations that are significant at the $95 \%$ confidence level are plotted. 
boundary regions of the subpolar gyre, and the Mann eddy region (Figure 3f). However, in these regions diffusion and bolus transports contribute substantially to the heat budget, and the sum $C_{\mathrm{ek}}+C_{g}+Q_{\mathrm{net}}$ does not explain much of the variance of $H_{t}$ (see Fig. 1f), so we do not consider these regions further. The terms $C_{\mathrm{ek}}^{v}$ and $Q_{\text {net }}$ are correlated over broad regions of the subtropical and subpolar gyres and are anticorrelated over the tropics (Fig. 5c) - patterns that are almost identical to correlation patterns between $C_{\mathrm{ek}}$ and $Q_{\text {net }}$ (see Fig. 7c in BPFH). This result confirms the hypothesis of BPFH that observed correlations between $C_{\mathrm{ek}}$ and $Q_{\mathrm{net}}$ are due to the role of the winds in controlling variability in $C_{\mathrm{ek}}$ and $Q_{\text {net }}$.

Over much of the subtropical gyre interior, monthly anomalies of $C_{g}$ are primarily due to $C_{g}^{v}$ (Fig. 3g), but, over the Gulf Stream path and a number of subpolar regions, $C_{g}^{T}$ also plays a significant role (Fig. $3 \mathrm{~h}$ ). In areas where $C_{g}^{T}$ is important, it is highly anticorrelated with $C_{g}^{v}$ (Fig. 5d). The term $C_{g}^{v T}$ is negligible everywhere except isolated shallow boundary regions (Figs. $3 \mathrm{i}$ and $5 \mathrm{~b}$ ).

The anticorrelation between $C_{g}^{v}$ and $C_{g}^{T}$ can be understood by writing $C_{g}$ in advective form:

$$
C_{g}=-\rho_{o} C_{p} \int_{-D}^{\eta}\left(\mathbf{u}_{g}, w_{g}\right) \cdot \nabla \theta d z
$$

We then note that $C_{g}$ is dominated by horizontal convergences (not shown), which is not surprising since to leading order the geostrophic flow is horizontally nondivergent (the small divergence of $\mathbf{u}_{g}$ is due to meridional variations in the Coriolis parameter). Therefore, we can use the geostrophic relation to write $\mathbf{u}_{g}$ in terms of the pressure field $p$ :

$$
C_{g} \approx-\frac{C_{p}}{f} \int_{-D}^{\eta}(\hat{\mathbf{z}} \times \nabla p) \cdot \nabla \theta d z .
$$

Geostrophic heat advection is determined by the magnitude of $\mathbf{u}_{g}$ and $\boldsymbol{\nabla} \theta$ (the spacing between isobars and isotherms, respectively) and the angle between isobars and isotherms (zero heat advection if isobars and isotherms are aligned and maximal heat advection if they are perpendicular) (Holton 2004). Time mean and monthly anomalies of $p$ and $\theta$ are plotted at several depth levels in Fig. 6. Contours of $p$ and $\theta$ are approximately aligned (both the mean and the time variable parts). However, when we decompose $C_{g}$ into portions that are due to temperature and velocity variability, it is apparent that contours of $p^{\prime}$ and $\bar{\theta}$ (cf. colored contours of $\bar{\theta}$ in Figs. 6a,c,e with black contours of $p^{\prime}$ in Figs. 6b,d,f) and $\bar{p}$ and $\theta^{\prime}$ (cf. black contours of $\bar{p}$ in Figs. 6a,c,e with color contours of $\theta^{\prime}$ in Figs. 6b,d,f) are not aligned, leading to large projections, which partially cancel each other. Note that, where $p$ and $\theta$ contours are exactly aligned ( $p$ is a linear function of $\theta$ ), $C_{g}=0$ and $C_{g}^{v}$ and $C_{g}^{T}$ are exactly anticorrelated (to the extent that $C_{g}^{v T}$ is negligible).

In summary, linear advective convergences $C_{\text {lin }}$ can be separated into Ekman $\left(C_{\mathrm{ek}}\right)$ and geostrophic $\left(C_{g}\right)$ components, as well as portions that are due to velocity variability, temperature variability, and their covariability. The terms $C_{\mathrm{ek}}$ and $C_{g}$ are both largest along the Gulf Stream path and in boundary regions, but $C_{\mathrm{ek}}$ is also significant in gyre interiors. Outside the tropics, $C_{\mathrm{ek}}$ is dominated by velocity variability $C_{\mathrm{ek}}^{v}$, indicating that this term is primarily due to local wind forcing. Both $C_{g}^{v}$ and $C_{g}^{T}$ play a role in setting $C_{g}$, and these terms are highly anticorrelated. The anticorrelation can be understood dynamically from the nature of geostrophic advection [see Eq. (6) and Fig. 6]. In fact, a relationship between $C_{g}^{v}$ and $C_{g}^{T}$ is expected since, by the thermal wind relation, geostrophic currents are related to gradients in temperature/density. These results suggest that separating $C_{g}$ into portions that are due to temperature and velocity variability (e.g., Qiu 2000; Dong and Sutton 2002) is not meaningful, and one should instead consider $C_{g}$ as a whole. Furthermore, separating full advective convergences into portions that are due to temperature and velocity variability (e.g., Dong and Sutton 2002; Doney et al. 2007) is not particularly meaningful in regions where geostrophic heat transport convergences are significant.

Table 1 shows the variance of the dominant terms in the heat budget averaged over the North Atlantic basin (north of $15^{\circ} \mathrm{N}$ ) in regions where the fraction of the variance of $H_{t}$ explained by $Q_{\mathrm{net}}+C_{\mathrm{ek}}+C_{g}$ is greater than 0.7 (see Fig. 1f), thus focusing on regions where diffusion and bolus transports are negligible and $C_{\text {lin }} \approx$ $C_{\text {ek }}+C_{g}$ (see section 2). Although variability of $Q_{\text {net }}$ is larger than $C_{\text {adv }}$ over the basin interior, $C_{\text {adv }}$ has much larger variability over regions of strong currents/fronts, and, averaged over the basin, the variances of these two terms are of comparable magnitude. Averaged over the basin, the variance of $C_{g}$ is somewhat larger than that of $C_{\mathrm{ek}}$, but both are important in setting $C_{\mathrm{adv}}$.

\section{Role of local forcing}

We now utilize our decompositions to estimate the relative roles of local atmospheric forcing and ocean dynamics in setting $H$. Our null hypothesis is that $H$ variability reflects the passive response to stochastic atmospheric forcing (Frankignoul and Hasselmann 1977; Cayan 1992a,b). Since ECCO is an ocean-only model, we cannot directly address the origin of the atmospheric forcing: specifically, whether the ocean plays a role in variability of air-sea fluxes of heat, momentum, 

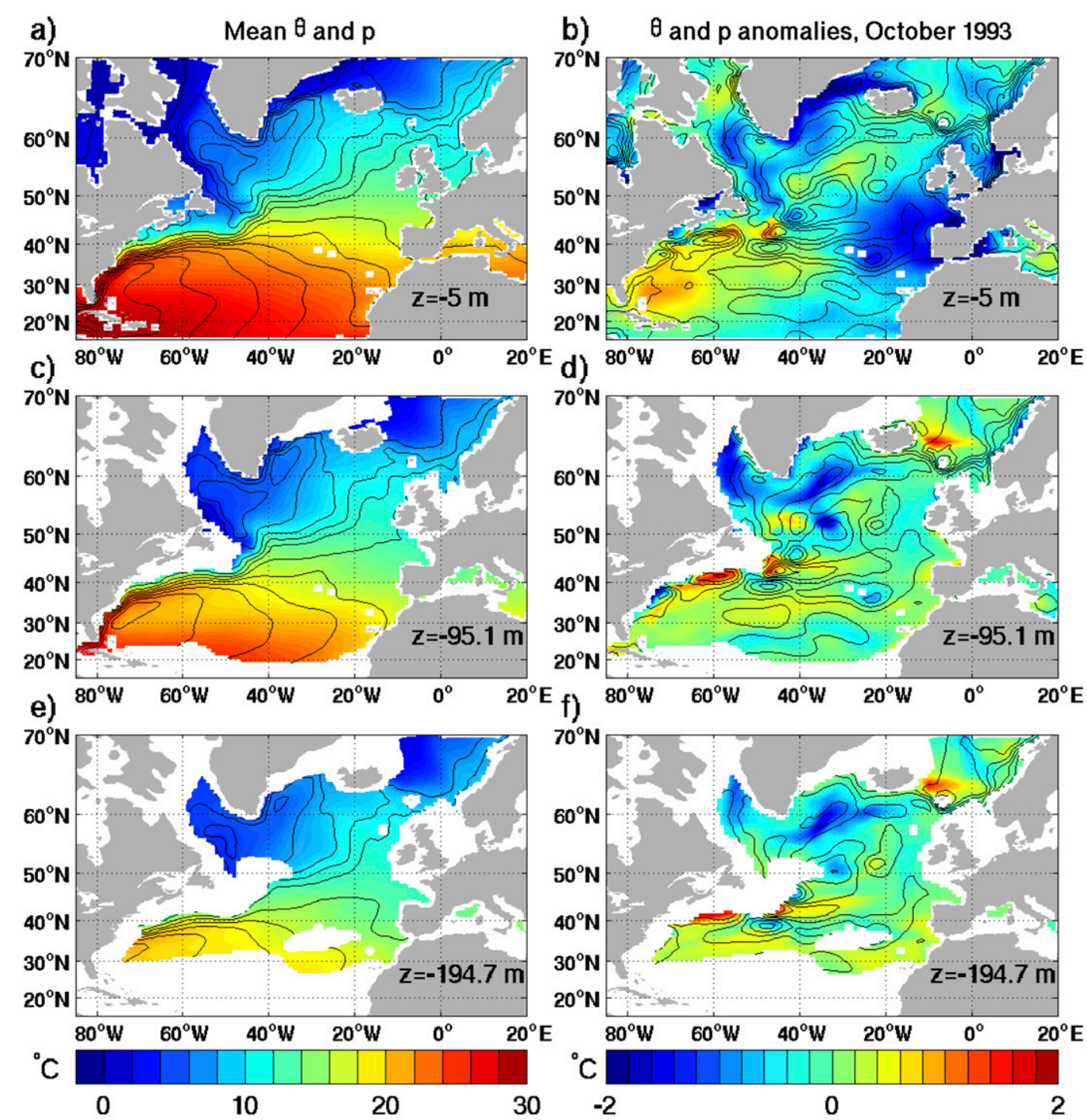

FIG. 6. Relationship between $p$ (black contours) and $\theta$ (colors) at several depth levels, indicating the magnitude of geostrophic heat advection: (left) time-mean $p$ and $\theta$ (absolute values of $p$ are arbitrary, and spacing of $p$ contours is $1 \mathrm{~m}^{2} \mathrm{~s}^{-2}$ ) and (right) monthly anomalies of $p$ and $\theta$ for a single month (October 1993; contour spacing of $p$ contours is $0.2 \mathrm{~m}^{2} \mathrm{~s}^{-2}$ ) at $z=(\mathrm{a}),(\mathrm{b})-5 \mathrm{~m},(\mathrm{c}),(\mathrm{d})-95.1 \mathrm{~m}$, and (e),(f) $-194.7 \mathrm{~m}$. Areas where $|z|>D$ are whited out since only areas where $|z|<D$ contribute to the heat budget for $H$.

and freshwater (here called the atmospheric forcing). However, previous work (Kushnir et al. 2002; Fan and Schneider 2012; Schneider and Fan 2012) demonstrates that the response of the extratropical atmosphere to midlatitude SST anomalies is relatively small in comparison with internal atmospheric variability, so as part of our null hypothesis we assume that variability in atmospheric fields is primarily stochastic in nature.

To evaluate our null hypothesis, we define $C_{\mathrm{loc}}^{*}=$ $Q_{\text {net }}+C_{\mathrm{ek}}^{v}$ as the impact of local atmospheric forcing on $H$. This hypothesis is slightly different than the hypothesis for the impact of local atmospheric forcing on $H$ proposed in BPFH, $C_{\text {loc }}=Q_{\text {net }}+C_{\text {ek }}$, because we exclude contributions to $C_{\mathrm{ek}}$ from temperature variability (i.e., $C_{\mathrm{ek}}^{T}$ ) as well as temperature and velocity covariability (i.e., $C_{\mathrm{ek}}^{v T}$ ). The reason for this is that we do not know a priori whether variability in the temperature field is the result of local atmospheric forcing. Furthermore, $C_{\text {loc }}^{*}$ can be calculated directly from atmospheric forcing and climatological temperature fields.

Over the interior of the subtropical and eastern subpolar gyres, over $70 \%$ of the variance of $H_{t}$ is explained by $C_{\mathrm{loc}}^{*}$ (Fig. 7a). The portion of the variance of $H_{t}$ explained by $C_{\mathrm{loc}}^{*}$ is quite similar to that explained by $C_{\mathrm{loc}}$ (Fig. 7b) because in most regions $C_{\mathrm{ek}}^{T}$ and $C_{\mathrm{ek}}^{v T}$ are much smaller than $C_{\mathrm{ek}}^{v}$. The term $C_{\mathrm{ek}}^{T}$ makes significant 
TABLE 1. Variances $\left[10^{3}\left(\mathrm{~W} \mathrm{~m}^{-2}\right)^{2}\right]$ of various terms in the budget for $H_{t}$ (area weighted) averaged over the North Atlantic basin (north of $15^{\circ} \mathrm{N}$ ) in regions where the fraction of the variance of $H_{t}$ explained by $Q_{\text {net }}+C_{\text {ek }}+C_{g}$ is greater than 0.7 (see Fig. 1f).

\begin{tabular}{ll}
\hline \hline Term & Variance \\
\hline$H_{t}$ & 2.30 \\
$Q_{\text {net }}$ & 1.04 \\
$C_{\text {adv }}$ & 1.06 \\
$C_{\mathrm{ek}}$ & 0.352 \\
$C_{g}$ & 0.630 \\
$C_{\text {loc }}^{*}$ & 1.62 \\
$C_{\text {loc }}$ & 1.62 \\
\hline
\end{tabular}

contributions to $C_{\text {ek }}$ in the tropics (Fig. 3e), but here $C_{\mathrm{ek}}$ is much smaller than $Q_{\text {net }}$ (cf. Figs. 1a and 1c) so that the fractions of the variance of $H_{t}$ explained by $C_{\text {loc }}$ and $C_{\mathrm{loc}}^{*}$ are still very similar. The term $C_{\mathrm{ek}}^{v T}$ makes significant contributions to $C_{\mathrm{ek}}$ in the Labrador Sea (see Fig. 3f), but here neither $C_{\text {loc }}$ nor $C_{\mathrm{loc}}^{*}$ explains much of the variance of $H_{t}$. Averaged over the North Atlantic basin, the variances of $C_{\mathrm{loc}}^{*}$ and $C_{\mathrm{loc}}$ (see Table 1 ) are comparable and substantially larger than the variance of $Q_{\text {net }}$ alone, indicating the importance of Ekman heat transport convergences in the basinwide heat budget.

It is important to note that $C_{\mathrm{loc}}^{*}$ is simply a hypothesis for the portion of $H_{t}$ that is due to local processes, and analyses of heat budgets in various regions and on various time scales will aid in determining whether this hypothesis is reasonable (see section 5). It is certainly possible that $C_{\mathrm{loc}}^{*}$ does not capture all of $H_{t}$ that is due to local atmospheric forcing. For example, $T$ anomalies that are locally forced will lead to locally forced components of $C_{\mathrm{ek}}^{T}$ and $C_{\mathrm{ek}}^{v T}$. Similarly, depending on location and time scale, portions of $C_{\text {loc }}$ may not reflect local forcing. Western boundary currents in particular are regions where we do not expect the null hypothesis to explain the majority of UOHC variability, as geostrophic convergences are important in the UOHC budget (Dong and Kelly 2004; Dong et al. 2007). At low frequencies, air-sea heat fluxes may damp SST anomalies created by geostrophic heat transport convergences (e.g., Tanimoto et al. 2003; Dong and Kelly 2004; Dong et al. 2007; Kwon et al. 2010). Since these fluxes are driven by the ocean, they should not be considered part of local atmospheric forcing.

In addition to the local thermodynamic interactions described above, the ocean may have dynamic impacts on the atmospheric circulation over certain regions-in particular, regions of strong currents and fronts. There is clear evidence that western boundary currents have impacts on the local and regional structures in the atmosphere [see reviews by Kelly et al. (2010) and Kwon et al. (2010)]. SST gradients impact wind stress (Xie 2004), wind stress convergence and curl (Chelton et al. 2004; Maloney and Chelton 2006; Small et al. 2008; Minobe et al. 2008, 2010; O'Neill et al. 2010), and cloud formation (Xie 2004; Small et al. 2008; Minobe et al. $2008,2010)$. Diabatic heating that is due to ocean-toatmosphere heat fluxes plays a role in maintaining atmospheric storm tracks (Hotta and Nakamura 2011). Furthermore, surface ocean currents impact wind stress, because the stress depends on the relative velocity of the atmosphere and the ocean (Kelly et al. 2001; Chelton et al. 2004). However, the impact of variability of western boundary currents on the atmosphere (Joyce et al. 2009) is just beginning to be quantified. While this subject is well beyond the scope of this paper, we will evaluate the extent to which wind stress anomalies forced by the ocean may be important in setting $C_{\mathrm{ek}}$ (see section 5).

\section{Regional analysis of $\boldsymbol{H}$ variability}

We now consider $H$ budgets over various regions in more detail. Gyre-scale regions are chosen in accord
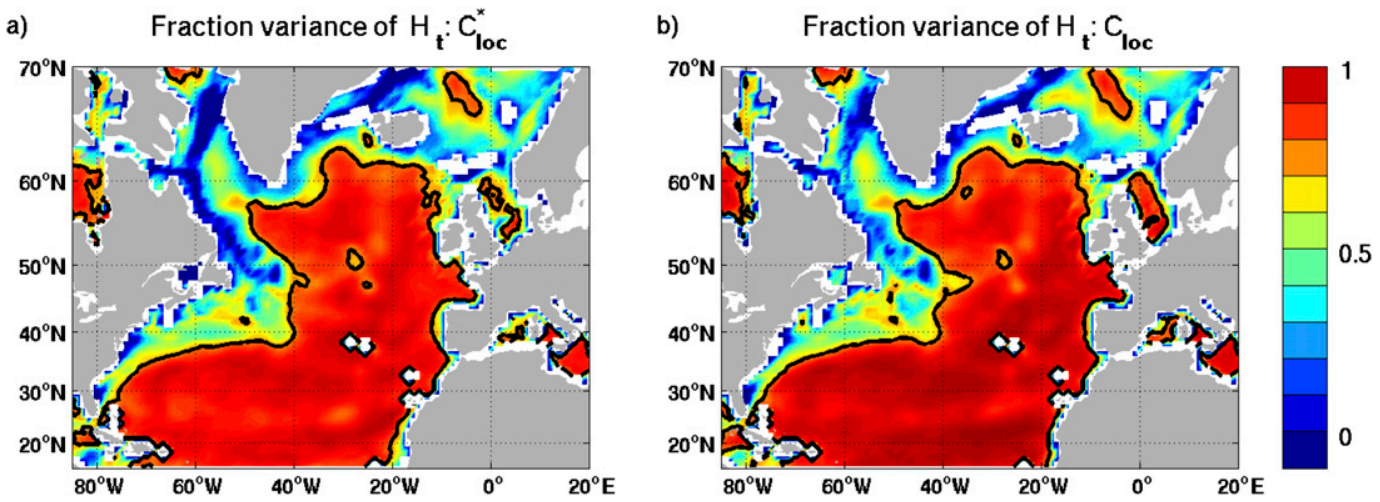

FIG. 7. Maps showing the fraction of the variance of $H_{t}$ explained by (a) $C_{\mathrm{loc}}^{*}$ and (b) $C_{\mathrm{loc}}$. Black contours are at levels of 0.7 . 

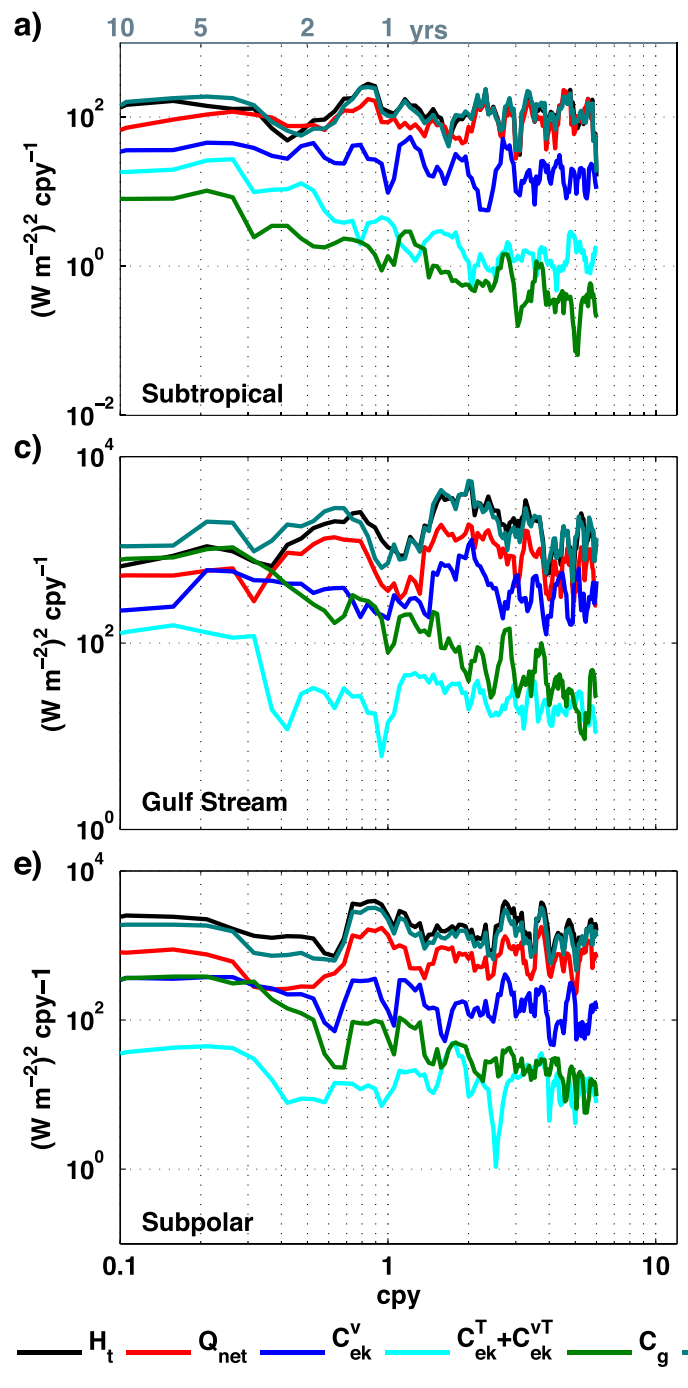

FIG. 8. (left) Power spectra of terms in $H_{t}$ budget and (right) coherence magnitude between $H_{t}$ and $Q_{\text {net }}, C_{\text {loc }}^{*}, C_{\text {loc }}$, and $C_{\mathrm{loc}}+C_{g}$ for (a),(b) the interior of the subtropical gyre, (c),(d) the Gulf Stream region, and (e),(f) the interior of the subpolar gyre. Dashed black lines indicate the $95 \%$ confidence level. Phase is near zero everywhere and hence is not plotted.

with the large-scale nature of the dominant modes of SST and $H$ variability (see EOFs of SST and $H$ in Figs. 3 and 4 of $\mathrm{BPFH}$ ) and the relatively homogenous values of the fraction of the variance explained by $C_{\mathrm{loc}}^{*}$ over broad regions (values near 0.7 in the interior of the subtropical and subpolar gyres and values on the order of 0.5 over the Gulf Stream region; see Fig. 7a). Following BPFH (see their Fig. 11a), we define three regions: 1) the interior of the subtropical gyre, 2) the Gulf Stream region, and 3) the interior of the eastern subpolar gyre. Gyre interiors are defined (somewhat unconventionally) by requiring that $C_{\mathrm{loc}}^{*}$ explain at least $70 \%$ of the variance of $H_{t}$ in order to focus on regions where similar dynamics are responsible for $H_{t}$ variability. (The specific threshold of $70 \%$ matches that of b)

d)

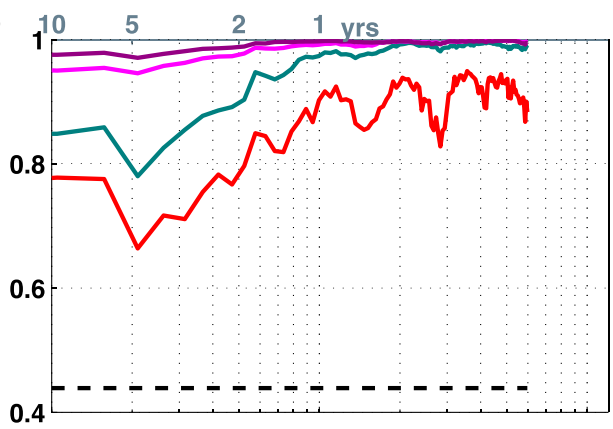

f)

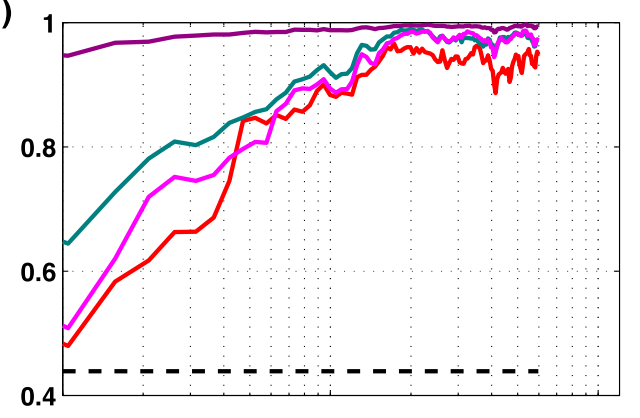

f)

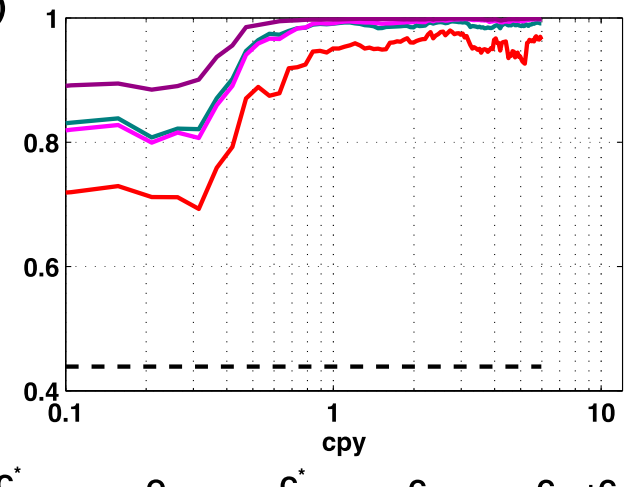


(Fig. 8a), consistent with temperature anomalies reflecting the integrated response to stochastic atmospheric forcing (Frankignoul and Hasselmann 1977). Similar spectral magnitudes and coherence magnitude of approximately 1 between $H_{t}$ and $C_{\mathrm{loc}}^{*}$ (see Figs. 8a,b) indicate that in the subtropical gyre $C_{\mathrm{loc}}^{*}$ explains most of the variability of $H_{t}$ for periods of less than 1-2 yr. For longer periods, coherence between $H_{t}$ and $C_{\mathrm{loc}}^{*}$ decreases while coherence between $H_{t}$ and $C_{\text {loc }}$ remains high, indicating that the term $C_{\mathrm{ek}}^{T}+C_{\mathrm{ek}}^{v T}$ plays an increasingly important role. Accordingly, temporally integrated budgets show more significant differences between the role of $T_{\mathrm{loc}}$ and $T_{\mathrm{loc}}^{*}$ in setting $T$. While $T_{\mathrm{loc}}$ explains $92 \%$ of the variance of $T, T_{\mathrm{loc}}^{*}$ explains only $78 \%$, which is slightly less than is explained by $T_{Q}$ alone $(82 \%)$. The reason for this is that $T_{\mathrm{ek}}^{v}$ and $T_{\mathrm{ek}}^{T}+T_{\mathrm{ek}}^{v T}$ are anticorrelated (correlation is -0.64 ), particularly at long time scales.

The question is whether $C_{\mathrm{loc}}^{*}$ or $C_{\mathrm{loc}}$ is a more appropriate measure of local atmospheric forcing in the subtropical gyre. Since the only terms that play a role in the budget for $T$ in this region are $T_{Q}$ and $T_{\mathrm{ek}}$, ocean dynamics (e.g., $T_{g}$ and diffusion/mixing) do not contribute to anomalies in the temperature field. Hence, $C_{\mathrm{ek}}^{T}$ and $C_{\mathrm{ek}}^{v T}$ are also the result of locally forced variability. This result suggests that in the subtropical gyre $C_{\mathrm{loc}}$ is a reasonable measure of local atmospheric forcing of $H$, and that $H$ anomalies are primarily due to local atmospheric forcing for all periods resolved by the ECCO estimate $(1 / 6 \leq \tau \leq 9.5 \mathrm{yr})$, confirming the result of BPFH.

In the Gulf Stream region and subpolar gyre, on intraannual time scales the dominant terms in the $H_{t}$ budget are $Q_{\mathrm{net}}$ and $C_{\mathrm{ek}}^{v}$, implying that anomalies are locally forced on these time scales (see Figs. 8c-f). The term $C_{\mathrm{ek}}^{T}+C_{\mathrm{ek}}^{v T}$ is negligible on all time scales resolved by ECCO (Figs. 8c,e), so $C_{\mathrm{loc}}^{*}$ and $C_{\mathrm{loc}}$ are indistinguishable. On interannual time scales, $C_{g}$ plays a role in the Gulf Stream region and subpolar gyre (Figs. 8c,e) and diffusion and bolus transports play a role in the subpolar gyre (see bottom-left panel of Fig. 12 in BPFH). The shape of the spectra of $H_{t}$ can be understood from various terms being important at different time scales; for example, in the Gulf Stream region the spectrum of $H_{t}$ is similar to that of $C_{\mathrm{loc}}^{*}$ on intra-annual time scales but is similar to that of $C_{g}$ on interannual time scales. Coherence between $H_{t}$ and $C_{\mathrm{loc}}^{*}$ abruptly decreases for periods that are longer than 1-2 yr (Figs. 8d,f), confirming the importance of ocean dynamics (primarily $C_{g}$ in the Gulf Stream region and $C_{g}$, diffusion, and bolus transports in the subpolar gyre).

The importance of ocean dynamics in setting variability $H$ in the Gulf Stream and subpolar gyre is emphasized by consideration of temporally integrated budgets (see Fig. 14 in BPFH). On interannual time scales, $T_{Q}$ reflects damping of SST anomalies that result from ocean dynamics-primarily geostrophic convergences in the Gulf Stream region and diffusion and bolus transports in the subpolar gyre. Therefore, these fluxes should not be considered part of local atmospheric forcing because they are not primarily set by internal atmospheric dynamics. The damping of SST anomalies formed by ocean dynamics also results in time series of $T-T_{o}$ that have significantly less variance on interannual time scales than those of $T_{g}$ and diffusion/ bolus transports (see left panels of Fig. 14 in BPFH), as $T-T_{o}$ is a small residual of ocean forcing and atmospheric damping.

A reviewer brought up the possibility that oceanic variability might play a role in setting wind stress variability on interannual time scales in regions of strong currents/fronts (e.g., the Gulf Stream region), through either the impact of SST on atmospheric winds (e.g., Chelton et al. 2004) or the direct impact of ocean currents on wind stress (e.g., Kelly et al. 2001); see also discussion in section 4 . If this is indeed the case, $C_{\mathrm{ek}}^{v}$ may not be entirely driven by the atmosphere. Although addressing the origin of wind stress variability is beyond the scope of this study, we can see that in the Gulf Stream region $C_{\mathrm{ek}}^{v}$ has relatively little power on interannual time scales, the time scale at which ocean dynamics are important in budgets for $H_{t}$ (see Fig. 8c). In fact, the coherences between $H_{t}$ and $Q_{\text {net }}, C_{\text {loc }}$, and $C_{\mathrm{loc}}^{*}$ are quite similar, indicating that whether Ekman transports are or are not considered to be part of local atmospheric forcing does not impact our results. Whether this result would hold in a higher-resolution model, in which boundary currents are more accurately represented, remains to be explored.

In summary, integrated over the subtropical gyre, $C_{\text {loc }}$ explains most of the variance of $H$ in the subtropical gyre, whereas $C_{\mathrm{loc}}^{*}$ does not, because Ekman heat transport convergences that are due to temperature variability and the correlation between velocity and temperature variability play a role in budgets of $H$ on interannual time scales. However, it is argued that, since ocean dynamics do not play a role in setting the temperature field in the subtropical gyre, in this case $C_{\mathrm{loc}}$ is a more appropriate definition of local atmospheric forcing. In accord with the result of BPFH, $H$ variability in the subtropical gyre is locally forced for all periods resolved by ECCO $(1 / 6 \leq \tau \leq 9.5 \mathrm{yr})$. In the Gulf Stream region and subpolar gyre, $C_{\mathrm{loc}}^{*}$ and $C_{\mathrm{loc}}$ are indistinguishable. In these regions, intra-annual $H$ anomalies are locally forced, but on interannual time scales ocean dynamics becomes important. On interannual time 
scales, air-sea heat fluxes reflect damping of SST anomalies that result from ocean dynamics, and these fluxes should not be considered to be part of local atmospheric forcing.

Our results have several implications for estimating the role of local atmospheric forcing from data. On intra-annual time scales, $C_{\text {loc }}^{*}$, which can be estimated from satellite winds and temperature climatologies, is a good approximation of the effects that result from local atmospheric forcing, except shallow boundary regions. However, on interannual time scales, estimating the effects of local forcing from data is more difficult for the following reasons:

1) In the subtropical gyre, Ekman heat transport convergences resulting from variability in the temperature field become important, and these transports appear to be the result of (integrated) local atmospheric forcing. Estimating these transports (so as to estimate $C_{\text {loc }}$ ) requires knowledge of the timevariable temperature field.

2) In the Gulf Stream region and the subpolar gyre, airsea heat fluxes reflect damping of SST anomalies formed by ocean processes, and thus air-sea heat fluxes are not locally forced (e.g., solely determined by local atmospheric variability).

\section{Conclusions}

This study examines the dynamical origins of variability in upper-ocean heat transport convergence in the North Atlantic on monthly to interannual time scalesa quantity of considerable relevance in coupled oceanatmosphere climate variability. As in BPFH, we base our analysis on a dynamically and kinematically consistent ocean state estimate covering the period 19922010 produced by the ECCO project. Upper-ocean heat content is defined as the heat contained in the layer between the surface and the maximum climatological mixed layer depth (integral denoted as $H$ ), that is, the ocean layers that are in communication with the atmosphere seasonally.

In the first part of the paper, (linear) advective heat transport convergences, as well as Ekman and geostrophic convergences, are decomposed into parts that are due to velocity variability, temperature variability, and their covariability. We find that partitioning heat transport convergences into portions that are due to temperature and velocity variability [as in Qiu (2000), Dong and Sutton (2002), and Doney et al. (2007)] is not useful where geostrophic convergences play a role. Both budget analyses and simple dynamical arguments related to geostrophic advection show that geostrophic heat transport convergences that are due to temperature and velocity variability are highly anticorrelated, and thus their separate treatment is not insightful. In contrast, Ekman heat transport convergences that are due to velocity variability, temperature variability, and their covariability have different dynamical origins: velocity variability reflects local wind forcing, whereas terms involving shifts in temperature gradients do not necessarily reflect local forcing. Ekman convergences are generally dominated by variability in Ekman mass transports, except in the tropics, where variability in the temperature field plays a sizable role, and in the Labrador Sea and Nordic seas, where the covariability between Ekman mass transports and the temperature field plays a sizable role.

The second part of the paper focuses on estimating the impact of local atmospheric forcing on $H$. The null hypothesis that $H$ reflects the passive response of the ocean to stochastic air-sea heat fluxes and Ekman heat transport convergence resulting from Ekman mass transport variability is assessed. We find that the null hypothesis can explain more than $70 \%$ of the variance of the tendency of $H$ over broad swaths of the North Atlantic, including the interior of the subtropical and subpolar gyres.

The final portion of the paper is dedicated to examining the terms that are important in setting $H$ variability as a function of region and time scale, focusing on three regions: 1) the interior of the subtropical gyre, 2) the Gulf Stream region, and 3) the interior of the subpolar gyre. In the subtropical gyre interior, the dominant terms in the heat budget are air-sea heat flux variability and Ekman heat transport convergences. Because ocean dynamics (geostrophic convergences, diffusion, and bolus transports) are negligible in this region, we argue that the full Ekman heat transport convergences reflect local atmospheric forcing, rather than just those due to Ekman mass transport variability. Local atmospheric forcing is found to explain the majority of the variance of $H$ over all time scales resolved by the ECCO estimate $(1 / 6 \leq \tau \leq 9.5 \mathrm{yr})$. In the Gulf Stream region and subpolar gyre interior, local forcing explains the majority of the variance of $H$ on intra-annual time scales. On interannual time scales, ocean dynamics become important-primarily geostrophic heat transport convergences in the Gulf Stream region and geostrophic transports, diffusion, and bolus transports in the subpolar gyre. Air-sea heat fluxes damp SST anomalies formed by ocean dynamics. Thus, these fluxes should not be considered to be part of local atmospheric forcing, because they are controlled by the ocean.

Our regional analysis of $H$ variability has three important implications: 
1) The time scale at which ocean dynamics becomes important in setting the ocean heat content depends strongly on region.

2) What terms constitute "local atmospheric forcing" of $H$ depends strongly on both region and time scale. For example, air-sea heat fluxes are set by local atmospheric variability on intra-annual time scales but are set by ocean processes on interannual time scales in some regions (e.g., in the Gulf Stream region).

3) The potential for the ocean to influence the overlying atmosphere depends strongly on region and time scale. On interannual time scales, damping of SST anomalies over the Gulf Stream region and subpolar gyre leads to large air-sea heat flux anomalies, which certainly influence the atmospheric boundary layer and potentially are communicated deeper into the atmosphere.

Acknowledgments. Funding for this work was provided by NOAA Grant NA10OAR4310199 and NA13OAR4310134 (Climate Variability and Predictability). Authors FG and PH were supported in part by NOAA Grant NA10OAR4310135 and NOPP/ NASA Grant NNX08AV89G. Support for the ECCO project provided by the NASA Physical Oceanography Program is also acknowledged. Funding for continuation of this work by MB at George Mason University was provided by NOAA (NA09OAR4310058 and NA14OAR4310160), NSF (1338427), and NASA (NNX14AM19G). We also acknowledge three anonymous reviewers whose insightful comments helped to improve the manuscript.

\section{REFERENCES}

Buckley, M. W., R. M. Ponte, G. Forget, and P. Heimbach, 2014: Low-frequency SST and upper-ocean heat content variability in the North Atlantic. J. Climate, 27, 4996-5018, doi:10.1175/ JCLI-D-13-00316.1; Corrigendum, 27, 7502-7525, doi:10.1175/ JCLI-D-14-00523.1.

Cayan, D. R., 1992a: Latent and sensible heat flux anomalies over the northern oceans: Driving the sea surface temperature. J. Phys. Oceanogr., 22, 859-881, doi:10.1175/ 1520-0485(1992)022<0859:LASHFA > 2.0.CO;2.

_ $1992 \mathrm{~b}$ : Latent and sensible heat flux anomalies over the northern oceans: The connection to monthly atmospheric circulation. J. Climate, 5, 354-369, doi:10.1175/1520-0442(1992)005<0354: LASHFA $>2.0 . \mathrm{CO} ; 2$.

Chelton, D. B., M. G. Schlax, M. H. Freilich, and R. F. Milliff, 2004: Satellite measurements reveal persistent small-scale features in ocean winds. Science, 303, 978-983, doi:10.1126/ science.1091901.

Doney, S. C., S. Yeager, G. Danabasoglu, W. G. Large, and J. C. McWilliams, 2007: Mechanisms governing interannual variability of upper-ocean temperature in a global ocean hindcast simulation. J. Phys. Oceanogr., 37, 1918-1938, doi:10.1175/JPO3089.1.
Dong, B., and R. Sutton, 2002: Variability in North Atlantic heat content and heat transport in a coupled ocean-atmosphere GCM. Climate Dyn., 19 (5-6), 485-497, doi:10.1007/ s00382-002-0239-7.

Dong, S., and K. A. Kelly, 2004: Heat budget in the Gulf Stream region: The importance of heat storage and advection. J. Phys. Oceanogr., 34, 1214-1231, doi:10.1175/ 1520-0485(2004)034<1214:HBITGS > 2.0.CO;2.

_, S. L. Hautala, and K. A. Kelly, 2007: Interannual variations in upper-ocean heat content and heat transport convergence in the western North Atlantic. J. Phys. Oceanogr., 37, 2682-2697, doi:10.1175/2007JPO3645.1.

Fan, M., and E. K. Schneider, 2012: Observed decadal North Atlantic tripole SST variability. Part I: Weather noise forcing and coupled response. J. Atmos. Sci., 69, 35-50, doi:10.1175/ JAS-D-11-018.1.

Foltz, G. R., and M. J. McPhaden, 2006: The role of oceanic heat advection in the evolution of tropical North and South Atlantic SST anomalies. J. Climate, 19, 6122-6138, doi:10.1175/JCLI3961.1.

Frankignoul, C., and K. Hasselmann, 1977: Stochastic climate models, part II: Application to sea-surface temperature anomalies and thermocline variability. Tellus, 29, 289-305, doi:10.1111/j.2153-3490.1977.tb00740.x.

Holton, J. R., 2004: An Introduction to Dynamic Meteorology. 4th ed. Academic Press, 535 pp.

Hotta, D., and H. Nakamura, 2011: On the significance of the sensible heat supply from the ocean in the maintenance of the mean baroclinicity along storm tracks. J. Climate, 24, 33773401, doi:10.1175/2010JCLI3910.1.

Jayne, S. R., and J. Marotzke, 2001: The dynamics of ocean heat transport variability. Rev. Geophys., 39, 385-411, doi:10.1029/ 2000RG000084.

Johns, W. E., and Coauthors, 2011: Continuous, array-based estimates of Atlantic Ocean heat transport at $26.5^{\circ} \mathrm{N}$. J. Climate, 24, 2429-2449, doi:10.1175/2010JCLI3997.1.

Joyce, T. M., Y.-O. Kwon, and L. Yu, 2009: On the relationship between synoptic wintertime atmospheric variability and path shifts in the Gulf Stream and the Kuroshio Extension. J. Climate, 22, 3177-3192, doi:10.1175/2008JCLI2690.1.

Kelly, K. A., S. Dickinson, M. J. McPhaden, and G. C. Johnson, 2001: Ocean currents evident in satellite wind data. Geophys. Res. Lett., 28, 2469-2472, doi:10.1029/2000GL012610.

, R. J. Small, R. M. Samelson, B. Qiu, T. M. Joyce, Y.-O. Kwon, and M. F. Cronin, 2010: Western boundary currents and frontal air-sea interaction: Gulf Stream and Kuroshio Extension. J. Climate, 23, 5644-5667, doi:10.1175/2010JCLI3346.1.

Kushnir, Y., W. A. Robinson, I. Bladé, N. M. J. Hall, S. Peng, and R. Sutton, 2002: Atmospheric GCM response to extratropical SST anomalies: Synthesis and evaluation. J. Climate, 15, 2233-2256, doi:10.1175/1520-0442(2002)015<2233: AGRTES $>2.0$. CO;2.

Kwon, Y.-O., M. Alexander, N. Bond, C. Frankignoul, H. Nakamura, B. Qiu, and L. A. Thompson, 2010: Role of the Gulf Stream and Kuroshio-Oyashio systems in large-scale atmosphere-ocean interaction: A review. J. Climate, 23, 32493281, doi:10.1175/2010JCLI3343.1.

Maloney, E. D., and D. B. Chelton, 2006: An assessment of the sea surface temperature influence on surface wind stress in numerical weather prediction and climate models. J. Climate, 19, 2743-2762, doi:10.1175/JCLI3728.1.

Minobe, S., A. Kuwano-Yoshida, N. Komori, S.-P. Xie, and R. J. Small, 2008: Influence of the Gulf Stream on the troposphere. Nature, 452, 206-209, doi:10.1038/nature06690. 
- M. Miyashita, A. Kuwano-Yoshida, H. Tokinaga, and S.-P. Xie, 2010: Atmospheric response to the Gulf Stream: Seasonal variations. J. Climate, 23, 3699-3719, doi:10.1175/ 2010JCLI3359.1.

O'Neill, L. W., D. B. Chelton, and S. K. Esbensen, 2010: The effects of SST-induced surface wind speed and direction gradients on midlatitude surface vorticity and divergence. J. Climate, 23, 255-281, doi:10.1175/2009JCLI2613.1.

Piecuch, C. G., and R. M. Ponte, 2012: Importance of circulation changes to Atlantic heat storage rates. J. Climate, 25, 350-362, doi:10.1175/JCLI-D-11-00123.1.

Qiu, B., 2000: Interannual variability of the Kuroshio Extension system and its impact on the wintertime SST field. J. Phys. Oceanogr., 30, 1486-1502, doi:10.1175/1520-0485(2000)030<1486: IVOTKE $>2.0 . \mathrm{CO} ; 2$.

Schneider, E. K., and M. Fan, 2012: Observed decadal North Atlantic tripole SST variability. Part II: Diagnosis of mechanisms. J. Atmos. Sci., 69, 51-64, doi:10.1175/JAS-D-11-019.1.
Small, R. J., and Coauthors, 2008: Air-sea interaction over ocean fronts and eddies. Dyn. Atmos. Oceans, 45 (3-4), 274-319, doi:10.1016/j.dynatmoce.2008.01.001.

Speer, K., and G. Forget, 2013: Global distribution and formation of mode waters. Ocean Circulation and Climate: A 21st Century Perspective, 2nd ed. G. Siedler et al., Eds., Elsevier, 211226.

Tanimoto, Y., H. Nakamura, T. Kagimoto, and S. Yamane, 2003: An active role of extratropical sea surface temperature anomalies in determining anomalous turbulent heat flux. J. Geophys. Res., 108, 3304, doi:10.1029/2002JC001750.

Wunsch, C., and P. Heimbach, 2013: Dynamically and kinematically consistent global ocean circulation and ice state estimates. Ocean Circulation and Climate: A 21st Century Perspective, 2nd. ed. G. Siedler et al., Eds., Elsevier, 553-580.

Xie, S.-P., 2004: Satellite observations of cool ocean-atmosphere interaction. Bull. Amer. Meteor. Soc., 85, 195-208, doi:10.1175/ BAMS-85-2-195. 